\title{
CORONARY ARTERY BYPASS WITHOUT CARDIOPULMONARY BYPASS FOR PATIENTS WITH ACUTE MYOCARDIAL INFARCTION
}

Rephael Mohr, MD

Yaron Moshkovitch, MD ${ }^{\mathrm{b}}$

Itzhak Shapira, $\mathrm{MD}^{\mathrm{a}}$

Gabriel Amir, MD

Hanoch Hod, MD

Jacob Gurevitch, MD
Objective: Between January 1992 and December 1994, 57 patients having an acute myocardial infarction with coronary anatomy suitable for coronary artery bypass grafting without cardiopulmonary bypass underwent this procedure within 1 week of the infarction. We describe the surgical results of these high-risk patients. Methods: The study population included 43 male patients $(75 \%)$ and 14 female patients $(25 \%)$ whose mean age was $\mathbf{5 8 . 5} \pm \mathbf{1 0 . 4}$ years. Thirty-two patients $(\mathbf{5 6 \%})$ underwent emergency bypass grafting within 48 hours of an acute myocardial infarction, 4 of them $(\mathbf{1 2 . 5 \%})$ as a bailout procedure after complicated percutaneous transluminal coronary angioplasty. Of these 32 patients, 7 patients $(22 \%)$ were in cardiogenic shock, and 10 patients $(31 \%)$ required preoperative intra-aortic balloon pump. Twenty-five patients (44\%) underwent coronary bypass grafting 2 to 7 days after an acute myocardial infarction. The mean number of grafts per patient was 1.8 (range, 1-4), and the internal thoracic artery was used in 47 patients $(82 \%)$. Only 7 patients $(12 \%)$ received grafts to a circumflex marginal branch. Results: Operative mortality was $1.7 \%$ (1 patient), and the mean postoperative hospital stay was $6.8 \pm 3$ days. One- and 5-year actuarial survivals were $94.7 \%$ and $82.3 \%$, respectively. Angina returned in 7 patients $(12 \%), 1$ of whom underwent reoperation. Multivariate analysis revealed renal failure and preoperative cardiogenic shock to be independent predictors of overall mortality. Old myocardial infarction and operation within the first $\mathbf{4 8}$ hours were independent predictors of overall unfavorable outcome events. Conclusions: These results suggest that coronary artery bypass grafting without cardiopulmonary bypass is a relatively low-risk procedure for patients having an infarction with coronary anatomy suitable for this technique. (J Thorac Cardiovasc Surg 1999;118:50-6) $\mathrm{n}$ the early days of coronary artery bypass grafting I $(\mathrm{CABG})$, surgical intervention within the first months of an acute myocardial infarction (AMI) was associated with increased mortality rates of $15 \%$ to $20 \% .^{1}$ Surgical deaths of patients having AMI then

From The Department of Thoracic and Cardiovascular Surgery, Tel Aviv Sourasky Medical Center, Tel Aviv, ${ }^{a}$ and The Heart Institute, The Chaim Sheba Medical Center, Tel Hashomer, ${ }^{b}$ affiliated to the Sackler Faculty of Medicine, Tel Aviv University, Tel Aviv, Israel.

Received for publication Sept 17, 1998; revisions requested Nov 4, 1998; revisions received March 3, 1999; accepted for publication March 3, 1999.

Address for reprints: Rephael Mohr, MD, The Department of Thoracic and Cardiovascular Surgery, Tel Aviv Sourasky Medical Center, 6 Weizman St, Tel Aviv 64239, Israel.

Copyright (C) 1999 by Mosby, Inc.

$0022-5223 / 99 \$ 8.00+0 \quad \mathbf{1 2 / 1 / 9 8 4 3 7}$ decreased with the improvement in myocardial preservation techniques and intra-aortic balloon counterpulsation. $^{2}$

Experience with early surgical revascularization (3 to 6 hours after AMI) began in 1971. Berg and colleagues ${ }^{3}$ reported a hospital mortality rate of $5.5 \%$ and 1-year mortality rate of $6.3 \%$. De Wood and colleagues 4 demonstrated a high incidence of intracoronary occlusive thrombus during the first few hours of an evolving AMI. Fresh thrombi were also removed from the coronary arteries of patients undergoing emergency CABG shortly after the appearance of symptoms. ${ }^{4}$ Enthusiasm for emergency $\mathrm{CABG}$ in evolving AMI has diminished with the advent and widespread use of intravenous thrombolytic therapy and percutaneous transluminal coronary angioplasty (PTCA). ${ }^{5}$ However, the failure of these measures in several cases and the appearance of 
Table I. Patient characteristics and overall (early and late) mortality rates $(n=57)$

\begin{tabular}{|c|c|c|c|c|c|c|c|}
\hline \multirow[b]{2}{*}{ Factor } & \multicolumn{2}{|c|}{ Prevalence } & \multicolumn{2}{|c|}{ Death with factor } & \multicolumn{2}{|c|}{ Death without factor } & \multirow[b]{2}{*}{$\mathrm{P}$ value } \\
\hline & $n$ & $\%$ of $n$ & $n$ & $\%$ & $n$ & $\%$ & \\
\hline Age $\geq 70 y$ & 12 & 21 & 4 & 33 & 5 & 11 & .06 \\
\hline Female gender & 16 & 28 & 3 & 20 & 6 & 15 & .702 \\
\hline Left main stenosis & 5 & 9 & 1 & 20 & 8 & 15 & .787 \\
\hline Unstable angina & 51 & 91 & 8 & 16 & 1 & 17 & .339 \\
\hline $\mathrm{AMI}<48 \mathrm{~h}$ & 32 & 56 & 7 & 22 & 2 & 8 & .154 \\
\hline Old MI & 31 & 56 & 7 & 23 & 2 & 8 & .070 \\
\hline Complicated PTCA & 13 & 23 & 3 & 23 & 6 & 14 & .412 \\
\hline $\mathrm{EF} \leq 35 \%$ & 19 & 33 & 4 & 21 & 5 & 13 & .441 \\
\hline Congestive heart failure & 23 & 42 & 4 & 17 & 5 & 16 & .861 \\
\hline Cardiogenic shock & 8 & 14 & 3 & 38 & 6 & 12 & .069 \\
\hline IABP & 14 & 43 & 4 & 29 & 5 & 12 & .202 \\
\hline Diabetes mellitus & 10 & 18 & 2 & 20 & 7 & 15 & .688 \\
\hline Hypertension & 21 & 37 & 3 & 14 & 6 & 17 & .812 \\
\hline Stroke & 1 & 2 & - & - & - & - & - \\
\hline PVD & 4 & 7 & 1 & 25 & 8 & 15 & .600 \\
\hline Calcified aorta & 4 & 7 & 1 & 25 & 8 & 15 & .600 \\
\hline Chronic renal failure & 2 & 4 & 2 & 100 & 7 & 13 & .023 \\
\hline Severe COPD & 3 & 5 & 0 & 0 & 9 & 17 & .441 \\
\hline Emergency surgery & 35 & 62 & 8 & 23 & 1 & 5 & .065 \\
\hline Nonused ITA & 11 & 20 & 3 & 27 & 6 & 13 & .245 \\
\hline Single graft & 22 & 39 & 3 & 14 & 6 & 17 & .724 \\
\hline Circumflex marginal graft & 7 & 12 & 1 & 14 & 8 & 16 & .907 \\
\hline
\end{tabular}

$E F$, Ejection fraction; $P V D$, peripheral vascular disease; COPD, chronic obstructive pulmonary disease; ITA, internal thoracic artery.

postinfarction angina reestablished the importance of $\mathrm{CABG}$ in the treatment of AMI.

Over the past few years, we have adapted a technique of performing CABG without cardiopulmonary bypass (CPB) and evaluated our use of it, especially in patients at high risk for conventional CABG. Among these high-risk patients, many were emergency cases after an AMI; some had cardiogenic shock, and some had intraaortic balloon counterpulsation and were in a compromised hemodynamic condition before the operation. Another group consisted of patients with an AMI whose condition had failed to respond to or had a contraindication to thrombolytic therapy. Altogether, a cohort of 57 patients underwent CABG without CPB within the first week of AMI between 1992 and 1994; this report describes their operative and late results.

\section{Patients and methods}

Between January 1992 and December 1994, 310 patients underwent $\mathrm{CABG}$ without CPB. One of us (R.M.) performed all the operations. This group comprises $16 \%$ of 1919 isolated CABG operations that had been carried out in our institution during this period. Fifty-seven patients with AMI underwent $\mathrm{CABG}$ without $\mathrm{CPB}$ within 1 week of the infarct. Most of the 1245 patients admitted with AMI to our intensive coronary care unit from 1992 through 1994 were treated conservatively ( $n=734$ patients) or with thrombolytic therapy ( $\mathrm{n}=$
425 patients). Only 67 patients were referred for CABG surgery, of whom 57 patients underwent operation without CPB (the preferred method at that time). Only 10 patients underwent $\mathrm{CABG}$ with $\mathrm{CPB}$ because it was not technically possible to perform the operation without it (4 patients underwent CABG plus mitral valve repairs and 6 patients had disease involving marginal branches of the circumflex artery, which were not suitable for operation without $\mathrm{CPB}$ ). Thus the selection of patients was by virtue of the patient's anatomic condition. Of the 57 patients with AMI who underwent operation without $\mathrm{CPB}$ within 1 week of the infarction, 32 procedures were emergency operations performed during the first 48 hours of an evolving AMI. Of these 32 patients, 7 patients (22\%) were in cardiogenic shock, 4 patients $(12.5 \%)$ underwent bailout PTCA, and 10 patients $(1 \%)$ required a preoperative intra-aortic balloon pump (IABP). The remaining 25 patients underwent operation between 2 and 7 days after the AMI, 1 patient (4\%) with cardiogenic shock and 4 patients $(16 \%)$ with preoperative IABP support. Patient characteristics are listed in Table I.

The diagnosis of AMI was made by the conventional electrocardiographic and enzyme criteria and was confirmed by coronary angiography that showed an occluded vessel with a regional wall motion abnormality on the left ventriculogram. Early reperfusion for AMI during those years was done by means of thrombolytic therapy or, in suitable cases, with primary PTCA. Surgical reperfusion was reserved for patients with a contraindication for thrombolytic therapy and signifi- 
cant wall motion abnormalities on echocardiography, for patients with cardiogenic shock, and for patients with hemodynamic instability. Two other groups of patients were those with ongoing pain after late admission to the emergency department (more than 6 hours after onset of pain) and patients with post-AMI angina with left ventricular dysfunction and a large area of myocardium at risk.

After cardiac catheterization, surgical intervention in those patients was a second option after PTCA or a first option for patients with coronary lesions not suitable for primary PTCA (these included left main complicated lesions and multiple lesions). The decision to perform $\mathrm{CABG}$ without $\mathrm{CPB}$ was primarily based on the potential benefit of avoiding CPB, under the assumption that the higher the risk from conventional $\mathrm{CABG}$, the greater the patient will profit from avoiding CPB. Feasibility of the procedure was determined by the size (diameter, $\geq 1.5 \mathrm{~mm}$ ) and accessibility of the vessel and the number of the coronary vessels to be bypassed. When there was greater potential benefit from avoiding CPB, a lesser degree of feasibility was accepted.

Surgical technique. General anesthesia was induced with midazolam (Dormicum; Hoffmann-LaRoche Ltd, Basel, Switzerland) and moderate dose (20-30 $\mu \mathrm{g} / \mathrm{kg})$ fentanyl (Beatryl; Abic, Netanya, Israel). Anesthesia was maintained with inhalational agents (halothane or isoflurane) and fentanyl $(100 \mu \mathrm{g} / \mathrm{h})$. Body hypothermia was avoided by adjusting room temperature, placing the patient on a warming mattress, and infusing warm solutions. The major hemodynamic consideration was to maintain systemic blood pressure above $100 \mathrm{~mm} \mathrm{Hg}$ to maintain adequate coronary perfusion. Neither $\beta$-blockers or calcium channel blockers were used to slow the heart rate. Heparin was administered in a dose of 2 to 3 $\mathrm{mg} / \mathrm{kg}$ weight before the internal thoracic artery and/or the saphenous veins were harvested to keep activated clotting time greater than 400 seconds. After heparinization, all the blood was collected with a pump suction to a cardiotomy reservoir and immediately returned to the patient through a central venous line. Heparin was reversed with protamine at the end of the procedure.

The operation was usually performed through a midline sternotomy. To facilitate exposure of the circumflex coronary territory, 3 patients underwent operation through a left thoracotomy, and 1 patient underwent reoperation through a midline sternotomy with extension of the incision to the fifth left intercostal space. In the former approach, proximal anastomosis of vein grafts was performed on the descending aorta, whereas in the latter it was performed on the ascending aorta. Exposure of the marginal branches of the circumflex coronary system was achieved by gentle, gradual rotation of the heart.

Hemodynamic instability, which primarily occurred during exposure of the marginal branches of the circumflex coronary artery, was managed by rapid fluid administration, use of dobutamine or epinephrine, infusion of glucose-insulinpotassium solution, prior grafting of the internal thoracic artery to the left anterior descending coronary artery whenever necessary, or most effectively, intraoperative insertion of an IABP for the duration of distal anastomosis construction. This was done either through the groin or, preferably, through the ascending aorta. For this purpose, in 4 patients the IABP was inserted intraoperatively after midline sternotomy and removed before sternal closure. Exposure and fixation of the anastomotic site were achieved with numerous superficial (40 silk) sutures. Deep sutures (3-0 Ti-Cron polyester fiber; Davis \& Geck, Danbury, Conn) were used to retract the right coronary artery. A hemostatic tourniquet (5-0 polytetrafluoroethylene [PTFE*] or Prolene [Ethicon, Inc, Somerville, $\mathrm{NJ}]$ ) and spurts of air were used to obtain a bloodless anastomotic field. The hemostatic sutures were tightened just after arteriotomy to shorten the regional ischemic time. Distal anastomosis was performed with 7-0 or 8-0 Prolene continuous suture, and proximal anastomosis was performed with 50 Prolene suture, with a partial occluding clamp. In cases of a calcified aorta, every effort was made to use pedicled in situ arterial grafts. In some patients, however, it was possible to palpate a skip area on the ascending aorta that could serve as a site for 1 proximal vein graft anastomosis, on the cupula of which other proximal anastomoses were constructed. To better detect skip areas, blood pressure was temporarily reduced by partial inflow occlusion with a cotton tape snare around the inferior vena cava.

Statistical analysis. Late follow-up was achieved by telephone questionnaire. Postoperative survival is expressed by the Kaplan-Meier method, and survival curves were compared by the log-rank test. The $\chi^{2}$ test was used to compare discrete (categoric) variables, and the $t$ test was used to compare continuous variables. Data are expressed as mean \pm SD. To predict death and unfavorable outcome events by various risk factors, logistic regression analysis was used. Hazard ratio (HR) and 95\% confidence interval (CI) were evaluated. Because one of the aims was to evaluate the association between each risk factor and survival time (controlling for other risk factors), Cox's proportional hazard model was used. All analyses were performed by SAS software (SAS PC, Version 6; SAS Institute, Cary, NC).

\section{Results}

The mean number of grafts per patient was 1.8. Only $12 \%$ of the patients received a graft to a marginal branch of the circumflex artery. Approximately 35\% (20 patients) received incomplete revascularization as a result of our not grafting the circumflex marginal branches (these patients had either very large hearts, which did not permit adequate rotation for exposure of the circumflex marginals, or they had marginal branches, less than $1.5 \mathrm{~mm}$ in diameter). Thus in spite of the fact that we had only 8 patients $(15 \%)$ with singlevessel disease, 22 patients (39\%) received a single graft. The remaining 14 patients had incomplete revascularization. Another reason for the relatively low per-

\footnotetext{
${ }^{*}$ W.L. Gore \& Associates, Inc, Flagstaff, Ariz.
} 
centage of circumflex marginal graftings stems from the fact that during the study period 10 patients in whom a graft to the distal circumflex system was essential were preselected to undergo operation with CPB. Ischemic time for grafting either the left anterior descending artery coronary system or the right coronary artery system was $9 \pm 4$ minutes (mean $\pm \mathrm{SD}$ ), and for the marginal branches of the circumflex system it was $14 \pm 5$ minutes (mean $\pm \mathrm{SD}$; Table II).

One patient $(1.7 \%$ ) died perioperatively (during hospitalization or within 30 days of operation). There were no strokes, sternal infections, or fatal AMIs in this series.

Hospital stay was $7 \pm 2$ days (mean $\pm \mathrm{SD}$ ), and the median stay was 6 days.

Late follow-up (1-69 months after the operation; mean, $46 \pm 9$ months) was achieved in 54 of the 56 hospital survivors $(96 \%)$. During this period, 8 patients $(14 \%)$ died, and 5 deaths $(9 \%)$ were cardiac related. One patient $(1.7 \%)$ had a nonfatal MI as the result of incomplete revascularization; in 7 patients (12\%), angina returned. Only 4 of the 7 patients with early return of angina underwent postoperative coronary recatheterization because the conditions of the other 3 patients were well controlled medically, and they were not referred for this procedure. In 2 of those 4 patients, the grafts were completely occluded; in 2 patients, all grafts were patent, and postoperative PTCA was performed in the native coronary arteries. One of the 4 patients who underwent catheterization later underwent reoperation.

Two patients (4\%) were found to have new symptoms of congestive heart failure as the result of a perioperative or late postoperative MI, and 1 of them eventually died. Of 54 hospital survivors who were available for follow-up, 43 patients (79\%) had an uneventful outcome and are currently feeling well.

Analysis of mortality and morbidity. Univariate analysis (Table I) and Cox regression analysis of overall (early and late) mortality events revealed several risk factors to be associated with decreased survival. Preoperative cardiogenic shock had an HR of 20.1 (95\% CI, 2.2-201). Chronic renal failure had an HR of 56.2 (95\% CI, 2.3-136.7). Of all risk factors (Table III), the independent risk factors for overall unfavorable outcome events were old MI (HR, 6.2; 95\% CI, 1.425.7) and operation within the first 48 hours of an evolving MI (HR, 6.2; 95\% CI, 1.4-28.8).

Kaplan-Meier analysis of the entire cohort showed 1and 5-year actuarial survival of $95 \% \pm 4 \%$ and $82 \% \pm$ $6 \%$, respectively (Fig 1). Five-year actuarial survival of patients who underwent operation during the first 48 hours of an evolving MI was only $77 \% \pm 9 \%$ compared
Table II. Operative data

\begin{tabular}{|c|c|c|c|}
\hline & $\begin{array}{c}C A B G \\
\text { within } 48 \mathrm{hr} \\
\text { of } A M I^{*}(\%)\end{array}$ & $\begin{array}{c}C A B G \\
\text { between 2-7d } \\
\text { after } A M I^{\dagger}(\%)\end{array}$ & $\begin{array}{c}\text { Total } \\
(\%)\end{array}$ \\
\hline \multicolumn{4}{|l|}{ No. of grafts } \\
\hline 1 & $9(28)$ & $12(48)$ & $21(36)$ \\
\hline 2 & $17(53)$ & $9(36)$ & $26(46)$ \\
\hline 3 & $5(15)$ & $4(16)$ & $9(15)$ \\
\hline 4 & $1(3)$ & $0(0)$ & $1(2)$ \\
\hline Mean \pm SD & $2.0 \pm 0.8$ & $1.6 \pm 0.7$ & $1.8 \pm 0.8$ \\
\hline Use of ITA & $24(75)$ & $23(92)$ & $47(82)$ \\
\hline Circumflex marginal graft & $3(9)$ & $4(16)$ & $7(12)$ \\
\hline \multicolumn{4}{|l|}{ Anastomosis time (min) } \\
\hline LAD or RCA & $8 \pm 4$ & $9 \pm 4$ & $8 \pm 4$ \\
\hline Circumflex marginal graft & $11 \pm 2$ & $16 \pm 4$ & $14 \pm 5$ \\
\hline Reoperative CABG & $0(0)$ & $1(4)$ & $1(2)$ \\
\hline $\begin{array}{l}I T A, \text { Internal thoracic artery; } L \\
\text { coronary artery. } \\
{ }^{*} \mathrm{n}=32 . \\
{ }_{\mathrm{t}} \mathrm{n}=25 . \\
{ }^{\mathrm{n}} \mathrm{n}=77 .\end{array}$ & $A D$, left anterio & or descending arter & $\mathrm{y} ; R C A$, right \\
\hline
\end{tabular}

with $91 \% \pm 5 \%$ in those who underwent operation between 2 and 7 days after AMI. However, the difference in late survival did not reach statistical significance (Fig 2).

\section{Discussion}

The early mortality rates in 57 patients who underwent operation in this series during the first week after AMI was $1.7 \%$. Only 1 of 32 patients $(3.1 \%)$ who underwent operation during the first 48 hours of an evolving MI died. Moreover, all 8 patients in this study with cardiogenic shock and all 13 patients who underwent operation after failed PTCA survived.

Several large series of CABG without CPB (beating heart surgery) were reported during the 1980s and the beginning of the 1990s. ${ }^{6-9}$ Gundry and associates ${ }^{10}$ recently reported that 7-year survival and cardiac death rates were similar for patients who underwent $\mathrm{CABG}$ with and without CPB. However, twice as many patients in the beating heart group required recatheterization and reintervention as the result of an inferior graft patency rate that may be related to snare injury in patients who underwent operation without CPB. Widespread use of the beating heart technique followed the advent of minimally invasive surgery and the introduction of the various new retractors and stabilizers, ${ }^{11,12}$ which may enhance future patency rates of beating heart operations. Although the adverse effects of $\mathrm{CPB}$ are minor and reversible in most patients, these effects may be of major importance, irreversible, and even fatal in high-risk patients. ${ }^{13}$ It is therefore reason- 
Table III. Total unfavorable events $(n=57)$

\begin{tabular}{|c|c|c|c|c|c|c|c|}
\hline \multirow[b]{2}{*}{ Factor } & \multicolumn{2}{|c|}{ Prevalence } & \multicolumn{2}{|c|}{$\begin{array}{l}\text { Unfavorable event } \\
\text { with factor }\end{array}$} & \multicolumn{2}{|c|}{$\begin{array}{c}\text { Unfavorable event } \\
\text { without factor }\end{array}$} & \multirow[b]{2}{*}{$\mathrm{P}$ value } \\
\hline & $n$ & $\%$ of $n$ & $n$ & $\%$ of $n$ & $n$ & $\%$ of $n$ & \\
\hline Age $\geq 70 \mathrm{yr}$ & 12 & 21 & 4 & 33 & 11 & 24 & .534 \\
\hline Female gender & 16 & 28 & 4 & 25 & 11 & 27 & .888 \\
\hline Left main stenosis & 5 & 9 & 1 & 20 & 14 & 27 & .737 \\
\hline Unstable angina & 51 & 91 & 13 & 26 & 2 & 33 & .787 \\
\hline $\mathrm{AMI}<48 \mathrm{~h}$ & 32 & 56 & 12 & 38 & 3 & 12 & .03 \\
\hline Old MI & 31 & 56 & 13 & 42 & 2 & 8 & .001 \\
\hline Complicated PTCA & 13 & 23 & 3 & 23 & 12 & 27 & .763 \\
\hline $\mathrm{EF} \leq 35 \%$ & 19 & 33 & 6 & 32 & 9 & 24 & .523 \\
\hline Congestive heart failure & 23 & 42 & 6 & 26 & 9 & 28 & .867 \\
\hline Cardiogenic shock & 8 & 14 & 4 & 50 & 11 & 22 & .101 \\
\hline IABP & 14 & 43 & 6 & 42 & 9 & 21 & .161 \\
\hline Diabetes mellitus & 10 & 18 & 2 & 20 & 13 & 28 & .617 \\
\hline Hypertension & 21 & 37 & 3 & 14 & 12 & 33 & .115 \\
\hline Stroke & 1 & 2 & - & - & - & - & - \\
\hline PVD & 4 & 7 & 1 & 25 & 14 & 26 & .951 \\
\hline Calcified aorta & 4 & 7 & 1 & 15 & 14 & 26 & .951 \\
\hline Chronic renal failure & 2 & 4 & 2 & 100 & 13 & 24 & .06 \\
\hline Severe COPD & 3 & 5 & 0 & 0 & 15 & 28 & .288 \\
\hline Emergency surgery & 35 & 62 & 12 & 34 & 3 & 17 & .085 \\
\hline Nonused ITA & 11 & 20 & 5 & 46 & 10 & 22 & .109 \\
\hline Single graft & 22 & 39 & 4 & 18 & 11 & 31 & .269 \\
\hline Circumflex marginal graft & 7 & 12 & 2 & 29 & 13 & 20 & .885 \\
\hline
\end{tabular}

$E F$, Ejection fraction; $P V D$, peripheral vascular disease; $C O P D$, chronic obstructive pulmonary disease; ITA, internal thoracic artery.

able to assume that avoiding CPB may be advantageous for certain subgroups of patients, especially those with risk conditions for conventional CABG. A major technical limitation of the use of the beating heart technique involves revascularization of the circumflex marginal. In those patients with marginal diameters greater than $1.5 \mathrm{~mm}$ and relatively small hearts, we can rotate the heart and perform the anastomosis. When the heart is larger than normal, it is easier to rotate the heart after the insertion of an IABP into the aorta. In spite of our belief that this is a safe procedure, for most of our patients who have significant disease of the cirumflex, we do prefer using CPB. Having said that, because of the risk associated with the use of CPB in certain patients, we sometimes do incomplete revascularization and do not perform circumflex anastomosis to avoid the use of the pump. In our previous report, we showed that avoiding the use of CPB may minimize the impact of several conventional risk factors on operative mortality rates. ${ }^{14}$ In our opinion, an important indication for $\mathrm{CABG}$ without $\mathrm{CPB}$ is an AMI. Early reports suggested that emergency CABG for an AMI was associated with a high operative mortality rate, ranging from $9 \%$ to as high as $60 \% .^{15-19}$ More recently, with improved anesthetic and surgical techniques, supportive pharmacologic therapy, and myocardial preservation, the perioperative mortality rate associated with emergency CABG in selected patients with AMI has fallen markedly. ${ }^{20}$

CABG performed within the first few hours of an AMI can be safe and have good results. Several articles $^{20-22}$ advocating surgical revascularization within 6 hours of AMI have shown improved hospital mortality rates $(3.8 \%$ vs $8 \%)$ and improved 10-year mortality rates $(8.2 \%$ vs $21 \%)$ in patients who underwent operation within 6 hours, as compared with those patients whose operation was delayed longer than 6 hours after an AMI. ${ }^{21-24}$ Conversely, medically treated patients had a $16 \%$ hospital mortality rate and an additional $14 \%$ mortality rate at 1 year. ${ }^{20}$

With the advent and widespread use of intravenous thrombolytic therapy or balloon angioplasty in patients with an evolving AMI, enthusiasm for emergency CABG in this setting has diminished. However, there continue to be several situations that require emergency or urgent surgical revascularization. For example, failure of thrombolytic agents and PTCA with acute occlusion may require surgical intervention. Additionally, early $\mathrm{CABG}$ for postinfarction angina has became common practice in the treatment of AMI. 


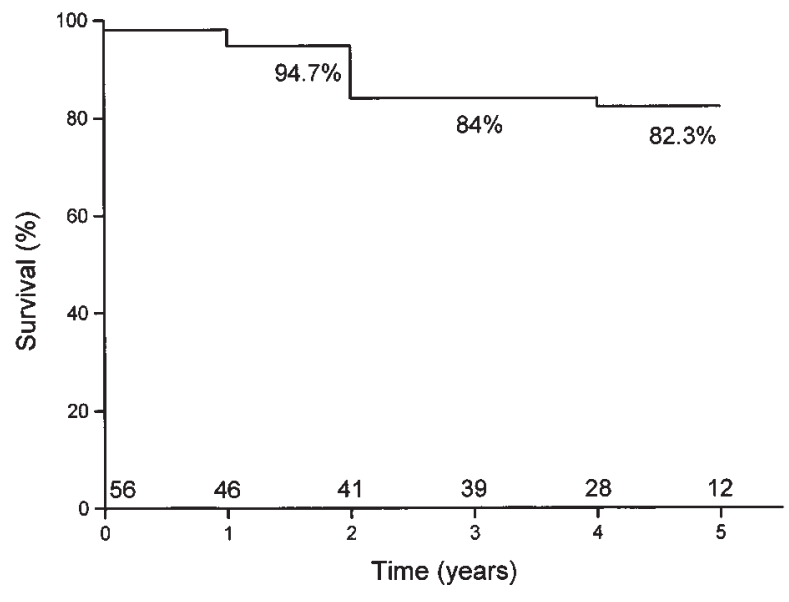

Fig 1. Survival curve (Kaplan-Meier) of the entire group.

The optimal timing of operation after AMI remains undecided. Nunley and associates ${ }^{23}$ found significant differences in outcome that depended on the time interval from AMI to operation; the mortality rate of patients who underwent operation within the first 48 hours of an AMI was 7.7\% compared with $0 \%$ after the first 48 hours. Creswell and colleagues ${ }^{25}$ suggested that the optimal timing is at least 2 weeks after AMI. In their study, mortality rates of patients who underwent operation within this 2 weeks was $6.5 \%$ compared with $2.9 \%$ in patients who underwent operation between 2 and 6 weeks after the AMI. In a recently published study of 1299 patients who underwent operation after an AMI in 19 Seattle-area hospitals, there was no difference in hospital mortality rates of patients who underwent operation during the first 24 hours after admission compared with those who underwent operation later during their hospital course $(8.3 \%$ vs $7.2 \% ; P$ $=.60) \cdot{ }^{26}$

Today, most patients are referred to the cardiac surgeon well after 6 hours have passed because they had an AMI. The reported overall mortality rates in these patients has varied: $3.4 \%,{ }^{27} 5 \%,{ }^{24} 7.2 \%,{ }^{26} 8.4 \%,{ }^{28}$ and $16 \% .{ }^{29}$ It is generally thought that the outcome in these patients may depend on factors such as the timing of the operation, left ventricular function, the presence of collaterals, and hemodynamic instability. In light of the better results obtained in the present study with the beating heart technique, the revascularization method appears to have contributed to improve the surgical outcome.

Our study showed that timing, in and of itself, is not a significant predictor of early or late mortality rates of CABG without $\mathrm{CPB}$ after AMI.

All patients who had an AMI in this report underwent

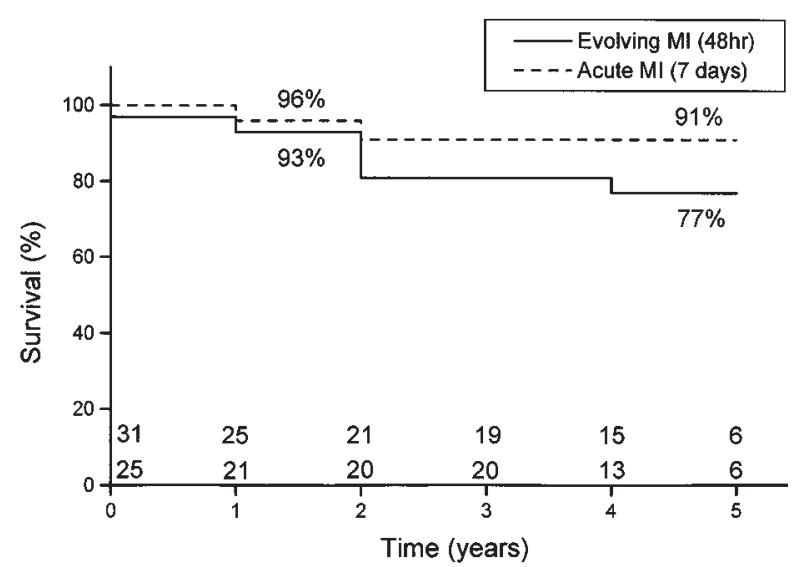

Fig 2. Survival curves by timing of revascularization.

operation after the first 6 golden hours of an evolving MI, and these results are comparable with those of De Wood and colleagues, ${ }^{21}$ which had been achieved within the first 6 hours (3.8\%) and may be better than those achieved with CPB in patients who underwent operation after the first 6 hours. ${ }^{24-26}$

Our mean follow-up period for this study was 4 years, a relatively long time for patients who had undergone $\mathrm{CABG}$ without $\mathrm{CPB},{ }^{10}$ and included most (96\%) of the patients. The good results of CABG without $\mathrm{CPB}$ in the patients with cardiogenic shock or IABP compared favorably with results of patients with cardiogenic shock who underwent operation by Sergeant and colleagues ${ }^{30}$ within the first 6 hours of an AMI. However, the late results of this subgroup in our study were not as good. Three of the 8 patients (37\%) with cardiogenic shock died between 1 and 5 years after the operation, and cardiogenic shock before the operation was found to be an important risk factor for overall mortality rates.

Timing of CABG after an AMI was found in our study to be related to postoperative unfavorable events; operations conducted within the first 48 hours were associated with an increased risk of such occurrences.

The term unfavorable events describes the sum of deaths, return of angina, reintervention, postoperative AMI, and appearance of new symptoms of congestive heart failure. The number of patients in each group was relatively small, which explains why the sum of unfavorable events appears to be a more sensitive indicator of poorer outcome than postoperative deaths. The poorer outcome of patients who underwent operation in the first 48 hours is probably related to surgical urgency. However, on the basis of the results reported earlier in 
this article, it may be prudent to postpone CABG without CPB to beyond the first 48 hours whenever clinically possible.

\section{REFERENCES}

1. Duvoisin GE, Everhart FJ, Rudy LW. Coronary embolectomy in fifteen cases of acute myocardial infarction [abstract]. Circulation 1974; 49(Suppl III):112.

2. DeWood MA, Notske RN, Hensley GR, Shields JP, O'Grady WP, Spores $\mathrm{J}$, et al. Intraaortic balloon counterpulsation with and without reperfusion for myocardial infarction shock. Circulation 1980;61:1105-12.

3. Berg R, Kendall RW, Duvoisin GE, Ganji JH, Rudy LW, Everhart FJ. Acute myocardial infarction: a surgical emergency. J Thorac Cardiovasc Surg 1975;70:432-9.

4. DeWood MA, Spores J, Notske R, Mouser LT, Burroughs R, Golden MS, et al. Prevalence of total coronary occlusion during the early hours of transmural myocardial infarction. N Engl $\mathrm{J}$ Med 1980;303:897-902.

5. Morris DC. Treatment of acute myocardial infarction by invasive cardiology techniques. Semin Thorac Cardiovasc Surg 1995;7: 184-90.

6. Benetti FJ, Naselli G, Wood M, Geffner L. Direct myocardial revascularization without extracorporeal circulation: experience in 700 patients. Chest 1991;100:312-6.

7. Buffolo E, Silver de Andrade FC, Branco JN, Teles CA, Aguiar LF, Gomes WJ. Coronary artery bypass grafting without cardiopulmonary bypass. Ann Thorac Surg 1996;61:63-6.

8. Laborde F, Abdelmeguid I, Piwnica A. Aortocoronary bypass without extracorporeal circulation: Why and when? J Cardiothorac Surg 1989;3:152-4.

9. Pfister AJ, Zaki MS, Garcia JM, Mispireta LA, Corso PJ, Qazi AG, et al. Coronary artery bypass without cardiopulmonary bypass. Ann Thorac Surg 1992;54:1085-91.

10. Gundry SR, Romano MA, Shattuck OH, Razzouk AJ, Bailey LL. Seven-year follow-up of coronary artery bypasses performed with and without cardiopulmonary bypass. J Cardiovasc Surg 1998; 115:1273-8.

11. Jansen EW, Borst C, Lahpor JR, Grundeman PF, Eefting FD, Nierich A, et al. Coronary artery bypass grafting without cardiopulmonary bypass using the octopus method: results in the first one hundred patients. J Thorac Cardiovasc Surg 1998;116: 60-7.

12. Calafiore AM, Di-Giammarco G, Teodori G, Gallina S, Maddestra N, Paloscia L, et al. Midterm results after minimally invasive coronary surgery (LAST operation). J Thorac Cardiovasc Surg 1998;115:763-71.

13. Kirklin JW, Barratt-Boyes BG. Cardiac surgery. 2nd edition. New York: Churchill Livingston; 1993. p. 83-97, 210-17, 337.

14. Moshkovitz Y, Lusky A, Mohr R. Coronary artery bypass without cardiopulmonary bypass: analysis of short-term and mid-term outcome in 220 patients. J Thorac Cardiovasc Surg 1995;110: 979-87.

15. Dawson JT, Hall RJ, Hallman GL, Cooley DA. Mortality in patients undergoing coronary artery bypass surgery after myocardial infarction. Am J Cardiol 1974;33:483-6.

16. Favaloro RG, Effler DB, Cheanvechai C, Quint RA, Sones FM J. Acute coronary insufficiency (impending myocardial infarction and myocardial infarction): surgical treatment by the saphenous vein graft technique. Am J Cardiol 1971;28:598-607.

17. Pifarré R, Spinazzola A, Nemickas R, Scanlon PJ, Tobin JR. Emergency aortocoronary bypass for acute myocardial infarction. Arch Surg 1971;103:525-8.

18. Miller MG, Hedley WJ, Weintraub RM, Restall DS, Alexander M. Surgery for cardiogenic shock. Lancet 1974;2:1342-5.

19. Dunkman WB, Leinbach RC, Buckley MJ, Mundth ED, Kantrowitz AR, Austen WG, et al. Clinical and hemodynamic results of intraaortic balloon pumping and surgery for cardiogenic shock. Circulation 1972;46:465-77.

20. Berg R, Selinger SL, Leonard JJ, Coleman WS, DeWood M. Acute evolving myocardial infarction: a surgical emergency. J Thorac Cardiovasc Surg 1984;88:902-6.

21. DeWood M, Selinger SL, Coleman WS. Surgical coronary reperfusion during acute myocardial infarction. In: McGoon D, editor. Cardiac surgery. 2nd edition. Philadelphia: FA Davis; 1987. p. 91-103.

22. DeWood MA, Spores J, Berg R, Kendall RW, Grunwald RP, Selinger SL, et al. Acute myocardial infarction: a decade of experience with surgical reperfusion in 701 patients. Circulation 1983;68(Suppl):II8-16.

23. Nunley DL, Grunkemeier GL, Teply JF, Abbruzzese PA, Davis JS, Khonsari S, et al. Coronary bypass operation following acute complicated myocardial infarction. J Thorac Cardiovasc Surg 1983;85:485-91

24. Lee JH, Murrell HK, Strony J, Cmolik B, Nair R, Lesnefsly E, et al. Risk analysis of coronary bypass surgery after acute myocardial infarction. Surgery 1997;122:675-801.

25. Creswell LL, Moulton MJ, Cox AL, Rosenbloom M. Revascularization after acute myocardial infarction. Ann Thorac Surg 1995;60:19-26.

26. Every NR, Maynard C, Cochran RP, Martin J, Weaver WD. Characteristics, management, and outcome of patients with acute myocardial infarction treated with bypass surgery: myocardial infarction triage and intervention investigators. Circulation 1996; 94(Suppl):II81-6.

27. Katz NM, Kubanick TE, Ahmed SW, Green CE, Pearle DL, Satler LF, et al. Determinants of cardiac failure after coronary bypass surgery within 30 days of acute myocardial infarction. Ann Thorac Surg 1986;42:658-63.

28. Pifarré R, Sullivan HJ, Montoya A, Bakhos M, Grieco JG, et al. Early myocardial revascularization for postinfarction angina Ann Thorac Surg 1987;44:159-63.

29. Hochberg MS, Parsonnet V, Gielchinsky I, Hussain SM, Fisch DA, Norman JC. Timing of coronary revascularization after acute myocardial infarction: early and late results in patients revascularized within seven weeks. J Thorac Cardiovasc Surg 1984; 88:914-21

30. Sergeant P, Blackstone E, Meyns B. Early and late outcome after CABG in patients with evolving myocardial infarction. Eur J Cardiothorac Surg 1997;11:848-56. 